\section{Reply to Dr Watenpaugh's Letter}

To the Editor:

We are most grateful for Dr Watenpaugh's interest in this topic, a novel-but currently untested-treatment suggestion. If inappropriately elevated plasma arginine vasopressin concentrations $\left([\mathrm{AVP}]_{\mathrm{p}}\right)$ are indeed the primary pathophysiological mechanism underlying exercise-induced hyponatremia (EAH), ${ }^{1}$ then ethanol ingestion would likely suppress AVP during and immediately following exercise. ${ }^{2}$ The downside of this treatment option is that it would likely take at least an hour before an ethanol-induced diuresis is initiated. ${ }^{2}$ For an athlete with altered mental status associated with EAH encephalopathy, this 60-minute latency may certainly increase the chances for neurological damage.

Although the administration of an intravenous bolus of hypertonic saline is not without significant risk (central pontine myelinolysis) as a treatment for chronic hyponatremia, cases of acute onset hyponatremia-such as most cases of EAH - have not been shown to carry equal risks. ${ }^{3}$ The 2 clear advantages of hypertonic saline over other potential treatment options such as vasopressin antagonists, isotonic saline, urea and fluid restriction remain that (1) the reversal of altered mental status occurs rapidly (minutes), ${ }^{4}$ and (2) it is efficacious regardless of the underlying mechanism (salt loss or fluid overload with or without inappropriate $[\mathrm{AVP}]_{\mathrm{p}}$ ).

We acknowledge the distinct wilderness advantages of using medicinal alcohol as a potential treatment for EAH (as a variant of the syndrome of inappropriate antidiuretic hormone hypersecretion [SIADH]) and agree that this option should be scientifically explored. We also believe that a more highly concentrated oral saline solution, such as the $125-\mathrm{mL} 9 \%$ saline broth shown to reverse symptoms and plasma sodium concentrations within 16-26 minutes, ${ }^{5}$ is also worthy of further investigation as a simple, quick and portable field option when intravenous 3\% saline administration is not possible.

\section{Tamara Hew-Butler, DPM, PhD, FACSM \\ Oakland University \\ Rochester, MI, USA \\ Ian R. Rogers, MBBS, FACEM \\ Sir Charles Gairdner Hospital \\ and \\ University of Western Australia \\ Perth, WA, Australia}

\section{References}

1. Hew-Butler T. Arginine vasopressin, fluid balance and exercise: Is exercise associated hyponatraemia a disorder of arginine vasopressin secretion? Sports Med. 2010;40:1-21.

2. Saini J, Boisvert P, Spiegel K, et al. Influence of alcohol on the hydromineral hormone responses to exercise in a warm environment. Eur J Appl Physiol. 1995;72:32-36.

3. Cheng JC, Zikos D, Skopicki HA, et al. Long-term neurological outcome in psychogenic water drinkers with severe symptomatic hyponatremia: the effect of rapid correction. Am J Med. 1990;88:561-566.

4. Hew-Butler T, Anley C, Schwartz P, et al. The treatment of symptomatic hyponatremia with hypertonic saline in an ironman triathlete. Clin J Sport Med. 2007;17:68-69.

5. Siegel AJ, d'Hemacourt P, Adner M, et al. Exertional dysnatremia in collapsed marathon runners: a critical role for point-of-care testing to guide appropriate therapy. Am J Clin Pathol. 2009;132:336-340. 